\title{
The Efficacy of Surgicel Compared with Simple Gauze Packing in Grade IV Liver Laceration; A New Hope for Trauma Patients: An Experimental Study
}

Hadi Khoshmohabat ${ }^{1}$, Alireza Makarem ${ }^{1,2}$, Mohammad Yasin Karami ${ }^{2}$, Hamid Reza Rasouli ${ }^{1}$, Zahra Danial ${ }^{1}$, Golnoosh Mahmoodizade ${ }^{2}$, Rohallah Rezaei ${ }^{2}$, Shahram Paydar $^{3}$, Seyede Niloofar Dastgheib ${ }^{2}$, Seyed Ali Hossein Zahraei ${ }^{*}$ and Zahra Shayan ${ }^{4}$

${ }^{1}$ Trauma Research Center, Baqiyatallah University of Medical Sciences, Tehran, Iran

${ }^{2}$ Student Research Committee, Shiraz University of Medical Sciences, Shiraz, Iran

${ }^{3}$ Trauma Research Center, Shiraz University of Medical Sciences, Shiraz, Iran

${ }^{4}$ Faculty of Medicine, Department of Community Medicine, Trauma Research Center, Shiraz University of Medical Sciences, Shiraz, Iran

*Corresponding author: Seyed Ali Hossein Zahraei, Student Research Committee, Shiraz University of Medical Sciences, Shiraz, Iran, Tel: +98713230 5410; E-mail: zmohsen14@gmail.com

Rec date: June 18, 2017; Acc date: August 02, 2017; Pub date: August 04, 2017

Copyright: (c) 2017 Khoshmohabat $\mathrm{H}$, et al. This is an open-access article distributed under the terms of the creative commons attribution license, which permits unrestricted use, distribution, and reproduction in any medium, provided the original author and source are credited.

\section{Abstract}

Background: The useful surgical hemostasis agent using in patients with grade 4 of the liver laceration is a challenging problem. This study assessed a topical hemostatic agent (Surgicel) using a partial hepatic laceration hemorrhage model. This experimental study compared the hemostatic effects of Surgicel and conventional gauze packing in hepatic parenchymal bleedings.

Methods: Twenty male Wistar albino rats (weight $250 \pm 50 \mathrm{~g}$ ) were randomly divided into two groups. Within each treatment group, surgicel or gauze packing (GP) $(n=10 /$ group) was applied to the liver laceration site that was created in the large lobe of the liver.

Results: There was statistically significant difference between two groups regarding the changes of before and after operation of $\mathrm{HCO} 3(\mathrm{P}=0.019)$. Across two groups, rats receiving surgicel lost less blood and formed clots more frequently than GP $(p<0.001)$.

Conclusion: Surgicel may be useful to treat hemorrhage from Liver lacerations in trauma patients.

Keywords: Surgicel; Liver laceration; Wounds; Injuries; Trauma

\section{Introduction}

Trauma is the main cause of death among people aged from 1 to 40 years [1]. According to the studies, the most common preventable cause of death in the trauma patients is bleeding [2]. In Trauma Patients, because of direct tissue damage of trauma that starts bleeding, trauma-induced coagulopathy also played a major role in the deaths of these patients [3]. So, interventions to control bleeding in trauma patients have great importance.

The most common site of intra-abdominal bleeding following penetrating or blunt abdominal injury due to Intra-abdominal organs injuries are especially the liver and spleen including cases that should be given priority in the study of traumatic injuries. The possibility of severe bleeding after injury of the liver is high because of its rich blood supply [4-6].

Although bleeding caused some damage to the liver parenchyma with methods such as electrocautery, simple suture and angiography embolization can be controlled, treating patients with complex liver damage, especially its deep lacerations, is still a topic challenging $[7,8]$. Abdominal packing as part of a damage-control laparotomy is a simple method that used to control bleeding following complex liver damage $[9,10]$.
Studies have shown that using liver packing with second-look laparotomy along with removal of packs inserted in the over $80 \%$ of patients with complex liver damage and coagulopathy simultaneously leads to success in control of bleeding [11].

There are several benefits to use packing, but intra-abdominal abscess and other complications such as sepsis after using it are probable. Research in this area with aims to find new methods to control bleeding due to liver damage (most commonly at risk of intraabdominal injury), will increase the effectiveness of existing approaches, identifying and removing side effects of the procedure continues.

In this context, the aim of this study was to investigate the effectiveness of external use of Surgicel (Surgicel is a hemostatic agent (blood-clot-inducing material) made of an oxidized cellulose polymer (the unit is poly-anhydroglucuronic acid).

It is also used by some boxing cut-men to control bleeding.) in comparison with gauze packing in grade 4 of Liver laceration bleeding in animal models of liver injury. It should be noted, according to a survey on existing research, this issue has not been studied. 
Citation: Khoshmohabat H, Makarem A, Karami MY, Rasouli HR, Danial Z, et al. (2017) The Efficacy of Surgicel Compared with Simple Gauze Packing in Grade IV Liver Laceration; A New Hope for Trauma Patients: An Experimental Study. J Trauma Treat 6: 387. doi: $10.4172 / 2167-1222.1000387$

Page 2 of 4

\section{Materials and Methods}

\section{Animals}

Twenty Wistar-Albino rats (all males, 3 months of age) at Shiraz University of Medical Sciences animal research laboratory, weight from $250 \mathrm{~g}$ to $300 \mathrm{~g}$, were included in this study. All the animals were housed individually and fed standard food throughout the experiment. The animals were initially evaluated for illness by physical examination and laboratory screening. The animals were purchased from the laboratory animal department of Iran's Pasteur Institute of Pharmacy. The animals lived in cages (one animal per cage) with water and food. They were monitored and acclimated to the new environment for 1 week. All the rats were maintained on standard rat chow and water. They were all housed under controlled standard laboratory conditions (temperature $20^{\circ} \mathrm{C}$ to $24^{\circ} \mathrm{C}$, relative humidity and $12 / 12$ hour light/dark cycle). The study was approved by the institutional review board and ethics committee of Shiraz University of Medical Sciences and the Ethics Committee of Natural Chemotherapeutics Research Laboratory of Iran's Ministry of Health. Study animals were handled in conformity with guidelines for the care and handling of laboratory animals provided by Shiraz Laboratory Animals Center by global standards for laboratory biosafety guidelines. Study Protocol In this experimental study, 20 male Wistar portion rats were randomly divided into two groups $(\mathrm{n}=10)$.

\section{Anesthesia and surgical procedure}

On the first day of experimentation, a $1 \mathrm{~cm}$ deep linear laceration was made on the large lobe in all rats by midline laparotomy immediately after induction of anesthesia with intramuscular injection of xylocaine and ketamine.

After 2 minutes of uncontrolled hemorrhage, the animals were randomized to application of gauze control (GC, n. 10), surgicel (CX, n.10) and packed in a standardized manner.

After 10 minutes, the packs were removed to calculate amount of shed blood. The animals then underwent damage control closure with packing in place. Forty-eight hours after initial damage control packing, the animals with gauze were returned to the operating room for pack removal. The need for repacking of the liver was assessed.

Blood samples were obtained at two different phases of the experiment:

Baseline and fourteen days after operation. Arterial and venous blood samples were analyzed with the hand-held iSTAT 1 Analyzer (Abbott Point of Care Inc., IL) and the Ac-T Hematology Analyzer (Beckman Coulter Inc., CA). Blood assays included hematocrit (Hct), platelet count and $\mathrm{pH}$.

\section{Statistical analysis}

The data were collected, analyzed and reported as the mean and standard deviation (mean $\pm \mathrm{SD}$ ) and proportions as appropriate. Statistical analysis was performed by the statistical package for social sciences (SPSS Inc., Chicago, USA) version 21.0 using Chi-Square Tests and Mann-Whitney Test. $\mathrm{p}<0.05$ was considered as statistically significant.

\section{Results}

The mean weight (gram) of the animals was $300 \pm 5.4$ and $290 \pm 4.3$ in the surgical and gaze groups, respectively. There was no difference in the preoperative body weights, the amount of liver removed, or the ratio of liver to body weight between groups.

The Mortality Ratio were 50\% (5/10) in gauze group and 10\% (1/10) in Surgical group that was not statistically significant ( $\mathrm{p}$-value $=0.14$ ). Mann-Whitney test indicated the amount of bleeding for the surgical group and the gauze group was statistically significant $(\mathrm{p}=0.001)$. Descriptive statistics of variables before operation (pre) and fourteen days after operation (post) has been mentioned in Table 1 .

\begin{tabular}{|l|l|l|l|l|}
\hline \multirow{2}{*}{ Variables } & \multicolumn{2}{l|}{ Surgicel } & \multicolumn{2}{l|}{ Guaze packing } \\
\cline { 2 - 5 } & N & Mean \pm SD & N & Mean \pm SD \\
\hline Hb-Pre & 10 & $19.3 \pm 1.49$ & 10 & $17.47 \pm 2.43$ \\
\hline Hb-Post & 9 & $12.75 \pm 5.56$ & 5 & $15.38 \pm 1.80$ \\
\hline HCT-Pre & 10 & $58.13 \pm 4.56$ & 10 & $52.8 \pm 7.28$ \\
\hline HCT-Post & 9 & $42.88 \pm 10.63$ & 5 & $46.6 \pm 5.41$ \\
\hline Bleeding & 10 & $0.42 \pm 0.16$ & 10 & $0.82 \pm 0.20$ \\
\hline PH-Pre & 10 & $7.21 \pm 0.05$ & 10 & $7.23 \pm 0.04$ \\
\hline PH-Post $^{2}$ & 9 & $7.35 \pm 0.06$ & 5 & $7.33 \pm 0.09$ \\
\hline HCO $_{3}$-Pre & 10 & $28.85 \pm 2.69$ & 10 & $28.19 \pm 3.96$ \\
\hline HCO $_{3}$-Post & 9 & $27.83 \pm 2.52$ & 5 & $25.76 \pm 3.71$ \\
\hline
\end{tabular}

Table 1: The Mean $\pm \mathrm{SD}$ of $\mathrm{Hb}, \mathrm{Hct}, \mathrm{Ph}, \mathrm{HCO}_{3}$ between two groups before operation (pre) and fourteen days after operation (post).

Before the treatment, there was no statistically significant difference between two groups in terms of $\mathrm{Hb}(\mathrm{p}=0.89)$, HCT $(\mathrm{p}=0.1), \mathrm{PH}$ $(\mathrm{p}=0.57)$ and $\mathrm{HCO}_{3}(\mathrm{p}=0.63)$. There were not statistically significant differences between two groups regarding the changes of before and after operation of $\mathrm{Hb}(\mathrm{p}=0.16)$, HCT $(\mathrm{p}=0.19), \mathrm{Ph}(\mathrm{p}=0.89)$. There was statistically significant difference between two groups regarding the changes of before and after operation of $\mathrm{HCO}_{3}(\mathrm{P}=0.019)$. Also measuring volumetric density in these two groups had done. We compared volumetric density $(\mathrm{Vv})$ in gauze and surgicel groups while fibrous and granulation tissues occupied the normal liver tissue (Table 2).

\begin{tabular}{|l|l|l|l|l|l|}
\hline Groups & PT & PN & P barrier & Vv barrier & Vv normal \\
\hline G1 & 165 & 163 & 2 & 0.01 & 0.99 \\
\hline G2 & 100 & 100 & 1 & 0.01 & 1.00 \\
\hline G4 & 96 & 96 & 1 & 0.01 & 1.00 \\
\hline G6 & 163 & 155 & 8 & 0.05 & 0.95 \\
\hline-- & -- & -- & -- & 0.02 & 0.98 \\
\hline S1 & 204 & 202 & 2 & 0.01 & 0.99 \\
\hline S2 & 233 & 228 & 5 & 0.02 & 0.99 \\
\hline S3 & 82 & 79 & 3 & 0.04 & 0.96 \\
\hline
\end{tabular}


Citation: Khoshmohabat H, Makarem A, Karami MY, Rasouli HR, Danial Z, et al. (2017) The Efficacy of Surgicel Compared with Simple Gauze Packing in Grade IV Liver Laceration; A New Hope for Trauma Patients: An Experimental Study. J Trauma Treat 6: 387. doi: $10.4172 / 2167-1222.1000387$

Page 3 of 4

\begin{tabular}{|l|l|l|l|l|l|}
\hline S4 & 55 & 50 & 5 & 0.09 & 0.91 \\
\hline S5 & 152 & 138 & 14 & 0.09 & 0.91 \\
\hline S6 & 217 & 196 & 21 & 0.10 & 0.90 \\
\hline S8 & 367 & 339 & 28 & 0.08 & 0.92 \\
\hline S9 & 391 & 339 & 62 & 0.16 & 0.84 \\
\hline-- & -- & -- & -- & 0.07 & 0.93 \\
\hline
\end{tabular}

recovered cellulose, ChitoFlex, Topical thrombin, Fibrin sealant, Tranexamic corrosive. Oxidized recovered cellulose (ORC) is a dry, absorbable sterile work (e.g., Surgicel) that can be connected specifically to a region of dying. A solitary layer sheet is completely invested in around 14 days [13]. Results are ideal if bleeding is insignificant (i.e., overflowing). By measuring volumetric density it is showed that using surgicel had a better result on prevention the fibrous and granulation tissues to occupy more normal tissue.

Table 2: Comparison of volumetric density between surgical and gauze groups.

\section{Discussion}

Topical hemostatic agents are utilized as an extra or contrasting option to standard suturing systems to control bleeding. Topical hemostatic agents are utilized when surgical homeostasis is deficient or unfeasible. The larger part of standard, elective operations are performed in patients with typical homeostasis and with insignificant blood loss. The two primary classifications of topical hemostatic agents are physical operators, who advance homeostasis utilizing a detached substrate, and organically dynamic operators, which upgrade coagulation at the bleeding site. Intraoperative bleeding is controlled utilizing standard surgical systems and electrocautery with the adjunctive utilization of topical hemostatic agents. Electrocautery may not be valuable for controlling bleeding in some surgical fields, for example, around nerves, medullary bone surfaces, needle-opening bleeding from vascular grafts. Patients who are anticoagulated and those with bleeding diatheses (e.g., factor insufficiencies, disseminated intravascular coagulation), or have platelet brokenness (e.g., Aspirin treatment) can keep on oozing from surgical surfaces despite satisfactory surgical hemostasis.

Under perfect conditions, patients with hemostatic variations from the norm have their fundamental deformities amended before continuing with surgery; be that as it may, this is not conceivable. Anticoagulated patients, patients getting antiplatelet treatment, and those with inherent or procured bleeding diatheses may require crisis surgical techniques to oversee injury or random conditions or to oversee discharge that is a consequence of their issue. Under these conditions, adjustment of the hemostatic imperfection is attempted on the way to or at the same time with the strategy. Hemostatic variations from the norm can likewise create over the span of surgery (e.g., hypothermia, dispersed intravascular coagulation). The more up to date oral anticoagulant drugs (rivaroxaban, apixaban, dabigatran), dissimilar to warfarin, don't have an inversion agent. Organically dynamic topical hemostats might be successful in this setting. Activated prothrombin complex concentrate or factor VIIa ought to be considered if all else fails in occurrences of life-undermining bleeding, for example, ruptured aortic aneurysm or intracranial bleeding [12].

Topical hemostatic specialists ought not to be utilized intravascular in light of the fact that they will bring about thrombosis or in bound spaces where development of the item could prompt to pressure. Physical specialists advance hemostasis through a few impacts. The framework material gives a boost that enacts platelets and the outward pathway and gives a platform to thrombus affidavit. The dry lattice likewise ingests water and aggregates hemostatic elements at the site of dying, and tamponades bleeding vessels by applying weight. The different physical operators incorporate the accompanying: Oxidized

\section{Conclusion}

ORC is ordinarily used to control bleeding at vascular anastomotic locales, the cut surfaces of strong organs, and retroperitoneal or pelvic surfaces after lymphadenectomy. Since ORC is malleable, it can be rolled and go effectively through laparoscopic trocars $[14,15]$ in vitro. We may think about having found that ORC has bactericidal action against an extensive variety of gram-positive and negative life forms due to its acidic $\mathrm{pH}[16,17]$. The low $\mathrm{pH}$ additionally restrains proteases and elastase, which might be useful in perpetual injuries; nonetheless, this same property may repress its resorption [18]. Lingering ORC is connected with disease and bond arrangement. In one investigation of 360 patients with postoperative pelvic sore, unabsorbed ORC was recognized as a hazard consider, and at times un-resorbed ORC was found at laparotomy over 12 months after it was set [19]. Abundance utilization of topical hemostatic specialists can block wound recuperating. Granuloma arrangement has been accounted for with the utilization of microfibrillar collagen, gelatin froth, and cyanoacrylate [20-22]. Also, the metabolites of cyanoacrylates (i.e., cyanoacetate and formaldehyde) can bring about a fiery reaction in the encompassing tissues.

\section{Conflict of Interest}

The authors had no conflict of interest.

\section{Acknowledgment}

The authors would like to acknowledge the Research Improvement Center of Shiraz University of Medical Science for improving the use of English in the manuscript.

\section{References}

1. Spinella PC, Holcomb JB (2009) Resuscitation and transfusion principles for traumatic hemorrhagic shock. Blood Rev 23: 231-240.

2. Sambasivan CN, Cho SD, Zink KA, Differding JA, Schreiber MA (2009) A highly porous silica and chitosan-based hemostatic dressing is superior in controlling hemorrhage in a severe groin injury model in swine. Am J Surg 197: 576-580.

3. Katrancha ED, Gonzalez LS (2014) Trauma-induced coagulopathy. Crit Care Nurse 34: 54-63.

4. Rossaint R, Cerny V, Coats TJ, Duranteau J, Fernández-Mondéjar E, et al. (2006) Key issues in advanced bleeding care in trauma. Shock 26: 322-331.

5. Uranüs S, Mischinger HJ, Pfeifer J, Kronberger L Jr, Rabl H, et al. (1996) Hemostatic methods for the management of spleen and liver injuries. World J Surg 20: 1107-1112.

6. Ochsner MG, Maniscalco-Theberge ME, Champion HR (1990) Fibrin glue as a hemostatic agent in hepatic and splenic trauma. J Trauma 30: 884-887.

7. Trunkey DD (2004) Hepatic trauma: Contemporary management. Surg Clin North Am 84: 437-450. 
Citation: Khoshmohabat H, Makarem A, Karami MY, Rasouli HR, Danial Z, et al. (2017) The Efficacy of Surgicel Compared with Simple Gauze Packing in Grade IV Liver Laceration; A New Hope for Trauma Patients: An Experimental Study. J Trauma Treat 6: 387. doi: $10.4172 / 2167-1222.1000387$

Page 4 of 4

8. Mohr AM, Lavery RF, Barone A, Bahramipour P, Magnotti LJ, et al. (2003) Angiographic embolization for liver injuries: Low mortality, high morbidity. J Trauma 55: 1077-1082.

9. Ordoñez C, Pino L, Badiel M, Sanchez A, Loaiza J, et al. (2012) The 1-2-3 approach to abdominal packing. World J Surg 36: 2761-2766.

10. Nicol AJ, Hommes M, Primrose R, Navsaria PH, Krige JE (2007) Packing for control of hemorrhage in major liver trauma. World J Surg 31: 569-574.

11. Adam DJ, Fitridge RA, Raptis S (2005) Intra-abdominal packing for uncontrollable haemorrhage during ruptured abdominal aortic aneurysm repair. Eur J Vasc Endovasc Surg 30: 516-519.

12. Lai A, Davidson N, Galloway SW, Thachil J (2014) Perioperative management of patients on new oral anticoagulants. Br J Surg 101: 742-749.

13. http://www.tisseel.com/us/clinical_evidence.html.

14. Sharma JB, Malhotra M (2003) Topical oxidized cellulose for tubal hemorrhage hemostasis during laparoscopic sterilization. Int J Gynaecol Obstet 82: 221-222.

15. Sharma JB, Malhotra M, Pundir P (2003) Laparoscopic oxidized cellulose (Surgicel) application for small uterine perforations. Int J Gynaecol Obstet 83: 271-275.
16. Sudmann B, Bang G, Sudmann E (2006) Histologically verified bone wax (beeswax) granuloma after median sternotomy in 17 of 18 autopsy cases. Pathology 38:138-141.

17. Wiseman DM, Kamp LF, Saferstein L, Linsky CB, Gottlick LE, et al. (1993) Improving the efficacy of INTERCEED Barrier in the presence of blood using thrombin, heparin or a blood insensitive barrier, modified Interceed (nTC7). Prog Clin Biol Res 381: 205-212.

18. Smeets R, Ulrich D, Unglaub F, Wöltje M, Pallua N (2008) Effect of oxidized regenerated cellulose/collagen matrix on proteases in wound exudate of patients with chronic venous ulceration. Int Wound $\mathrm{J} 5$ : 195-203.

19. Fagotti A, Costantini B, Fanfani F, Vizzielli G, Rossitto C, et al. (2010) Risk of postoperative pelvic abscess in major gynecologic oncology surgery: one-year single-institution experience. Ann Surg Oncol 17: 2452-2458.

20. Mannucci PM (1998) Hemostatic drugs. N Engl J Med 339: 245-253.

21. Nakajima M, Kamei T, Tomimatu K, Manabe T (1995) An intraperitoneal tumorous mass caused by granulomas of microfibrillar collagen hemostat (Avitene). Arch Pathol Lab Med 119: 1161-1163.

22. Edmonson MB (2001) Foreign body reactions to dermabond. Am J Emerg Med 19: 240-241. 